\title{
Are sports bettors looking at responsible gambling messages? An eye-tracking study on wagering advertisements
}

\author{
LISA LOLE*, EN LI, ALEX M. RUSSELL, NANCY GREER, HANNAH THORNE and NERILEE HING \\ School of Health Medical and Applied Sciences, Central Queensland University, Branyan, QLD, Australia
}

(Received: April 3, 2019; revised manuscript received: June 5, 2019; accepted: July 2, 2019)

\begin{abstract}
Background and aims: The broadcast of wagering advertisements during televised sports matches has been associated with various adverse outcomes. In order to counter these effects, legislative bodies require wagering operators to include responsible gambling messages in their advertisements; however, the effectiveness of these messages is unclear. This study sought to examine the extent to which responsible gambling messages are looked at, in the wider context of gambling advertisements. Methods: Forty-nine regular sports bettors and 10 non-gamblers viewed a series of sports betting advertisements, while an eye-tracker recorded the number of fixations placed on responsible gambling messages, as well as other text-based wagering content. Results: Responsible gambling messages were, generally, presented in a non-conspicuous manner. Eye-tracking data revealed that significantly fewer fixations were placed on responsible gambling messages, compared to wagering information $(p<.001)$; however, this effect did not differ according to level of gambling risk $(p=.169)$. The number of fixations placed on the different types of responsible gambling messages was found to vary, based on gambling risk $(p=.006)$, as well as, what appears to be, the physical characteristics of these messages. Discussion: Very few fixations were placed on, or near, responsible gambling messages, compared to other wagering information, meaning that, in their current form, they are unlikely to be effective in protecting against gambling harm. Preliminary evidence shows that presenting messages on a highcontrast/block-color background increases the number of fixations on these. Conclusion: Further research is needed to identify ways of increasing the effectiveness of responsible gambling initiatives in the sports betting context.
\end{abstract}

Keywords: responsible gambling, sports betting, wagering, advertising, gambling, eye-tracking

\section{INTRODUCTION}

The broadcast of wagering advertisements is prolific, especially during televised sports matches (Hing, Lamont, Vitartas, \& Fink, 2015b; Lopez-Gonzalez, Estévez, \& Griffiths, 2017b; Sproston, Hanley, Brook, Hing, \& Gainsbury, 2015). Sports betting promotions are one of the most common types of televised advertisements in Australia, and are considered to normalize the gambling experience, as well as prematurely expose young people to gambling (Derevensky, Sklar, Gupta, \& Messerlian, 2010; Hing, Vitartas, Lamont, \& Fink, 2014; Monaghan, Derevensky, \& Sklar, 2008). Viewing these advertisements is also associated with an increased desire to gamble among problem, moderate, and low-risk gamblers (Hing, Lamont, Vitartas, \& Fink, 2015a; Sproston et al., 2015). Interestingly, research has also indicated that these advertisements are more likely to encourage continued gambling, rather than enticing non-gamblers to take up the activity (Binde, 2009; Hing, Cherney, Blaszczynski, Gainsbury, \& Lubman, 2014). This is particularly concerning at the "problem" end of the gambling impact spectrum, where already quite severe gambling-related harm is likely to be exacerbated. Moreover, the constant availability of gambling, from any location, through smart devices, accompanied by increases in advertising, has been shown to be associated with increased participation in gambling behavior (Russell, Hing, Browne, \& Rawat, 2018), less perception of potential harm, and problematic gambling patterns (Browne, Hing, Russell, Thomas, \& Jenkinson, 2019; Hing, Russell, Thomas, \& Jenkinson, 2019), thus also presenting concerns for low- and moderate-risk gamblers (Productivity Commission, 2010).

Generally, wagering advertisements depict winning as easy, that gambling is a realistic way to become wealthy and/or achieve a "glamorous" lifestyle, and often use humor, celebrities, and/or experts to market their products (Binde, 2014; Sproston et al., 2015). Their content is also targeted to appeal to younger males (Hing, Russell, Vitartas, \& Lamont, 2016; Thomas, Lewis, McLeod, \& Haycock, 2012), the demographic with the highest numbers of sports bettors (Gainsbury et al., 2013; Humphreys \& Perez, 2012; Jenkinson, de Lacey-Vawdon, \& Carroll, 2018), and whom are most likely to experience gambling-related harm (Delfabbro, 2012; Johansson, Grant, Kim, Odlaug, \&

* Corresponding author: Lisa Lole; School of Health Medical and Applied Sciences, Central Queensland University, University Drive, Branyan, QLD 4670, Australia; Phone: +617 4150 7136; Fax: +617 4150 7080; E-mail: 1.lole@cqu.edu.au

This is an open-access article distributed under the terms of the Creative Commons Attribution-NonCommercial 4.0 International License, which permits unrestricted use, distribution, and reproduction in any medium for non-commercial purposes, provided the original author and source are credited, a link to the CC License is provided, and changes - if any - are indicated. 
Götestam, 2009; Williams, Volberg, \& Stevens, 2012; Williams, West, \& Simpson, 2012).

At this point in time, these advertisements are not banned altogether, at least in Australia, because sports betting and its advertising provide a stream of revenue for gambling operators, government, and media broadcasters and, arguably, because they provide information that is of interest to some adults (Australian Government Department of Communications and the Arts, 2017; Binde, 2014). Many jurisdictions have introduced restrictions on when these advertisements can be shown, as well as requiring them to include a responsible gambling message (e.g., Australian Association of National Advertisers, 2018; Australian Communications and Media Authority, 2018; Federal Register of Legislation, 1992). Thus, while the content of wagering advertisements emphasizes the positive aspects of the gambling experience (see Binde, 2014), responsible gambling messages are posited to counter such content by encouraging gamblers to be more aware of their actions, and to gamble in a way that is not excessive or harmful, to themselves or to others (Hing, Russell, \& Hronis, 2018; Reith, 2007, 2008).

To be effective in this aim, responsible gambling messages need to encourage gamblers to evaluate their behaviors through cognitive, emotional, and motivational processes (Delfabbro, 2008); however, the effectiveness of these messages in eliciting behavioral and/or attitudinal changes is unclear, as is whether viewers pay them any attention at all when watching sports betting advertisements. There is also debate over whether the content of such messages is appropriate, given that they generally place the sole responsibility of harmful behaviors on gamblers themselves, rather than the product/service, vendors, or government regulators, which serves to maintain gambling-related stigma (Campbell \& Smith, 2003; Hancock, Schellinck, \& Schrans, 2008; Hancock \& Smith, 2017; Livingstone \& Woolley, 2007; Reith, 2007, 2008; Schüll, 2012).

Responsible gambling research indicates that these messages are included on the websites of all licensed wagering operators in Australia, but only $12 \%$ of individual online wagering inducements were found to have a responsible gambling message within them (Hing, Sproston, Brook, \& Brading, 2017). Research within community gambling venues has shown that, although gamblers are generally aware of responsible gambling signage in such venues (Focal Research, 2004; Hing, 2003), their ability to recall the actual content of these messages, and to change their behaviors as a result of viewing these, is quite poor (Hing, 2003; Monaghan, 2004; Monaghan \& Blaszczynski, 2007; Steenbergh, Whelan, Meyers, May, \& Floyd, 2004; Williams \& Connolly, 2006).

At a minimum, responsible gambling messages need to easily attract attention, contain relevant and personally meaningful information, and suggest some course of action or precaution to avoid harm. There are several avenues through which responsible gambling is encouraged (see Hing, Russell, Li, \& Vitartas, 2018). For instance, research has demonstrated that the responsible gambling messages' physical attributes (e.g., the color and size of the message), their display in prominent locations, the presence of movement or action, and their ability to interrupt/compete with attention-grabbing gambling information are all features of responsible gambling information that aid recall and have the desired impact on cognitive processes (Bailey, Konstan, \& Carlis, 2001; Bartram, 2001; Clark \& Brock, 1994; Johnston \& Dark, 1986; Parke, Harris, Parke, Rigbye, \& Blaszczynski, 2014). In the context of electronic gaming machines, the use of pop-up responsible gambling messages to break-up play has been successfully used to encourage healthy gambling behaviors (Kim, Wohl, Stewart, Sztainert, \& Gainsbury, 2014; Stewart \& Wohl, 2012).

One of the most common methods of presenting responsible gambling information, in sports betting advertising, is through messages in written form; however, to date, previous research on their effectiveness has been largely lacking. This study was part of a larger project that specifically examined the reactions of sports bettors to wagering advertising and inducements. It sought to examine how much these responsible gambling messages are looked at, in comparison to other gambling-related, text-based messages that occur within the same advertisement (Rayner, Rotello, Stewart, Keir, \& Duffy, 2001). Despite a recent critical review of the literature concluding that examining the perceptions of responsible gambling information using eye-tracking methodology is a priority in the field of gambling research (Binde, 2014), this was the first study to use such methodology to investigate this element of gambling advertisements among community gamblers (see also Cuesta-Cambra, Manas-Viniegra, Nino-Gonzalez, \& Martinez-Martinez, 2019). The study also extends previous research by using psychophysiological measures to capture the number of fixations on such information by non-gamblers, non-problem gamblers, and at-risk gamblers.

It was hypothesized that significantly fewer fixations would be placed on responsible gambling messages, compared to other inducement offer (IO) information presented in the same advertisement (Bailey et al., 2001; Bartram, 2001; Clark \& Brock, 1994; Johnston \& Dark, 1986; Parke et al., 2014). The study also sought to describe the general characteristics of these responsible gambling messages, and whether these are associated with significantly more/less fixations placed on them. The hypothesis concerning this second aim was exploratory in nature.

\section{METHODS}

\section{Participants}

Participants were recruited for in-person testing through specialized market research panel providers. One provider recruited the first 54 participants, and the second recruited the final 6 participants. Participants were screened based on eligibility criteria provided by the research team (see below) through telephone calls. No information was provided to the research team in terms of refusal/screen-out rates.

To be eligible for inclusion, problem-, moderate-, and low-risk gambling participants were required to have bet on sports at least once a fortnight in the previous 12 months. Consistent with previous research on the prevalence of gambling activity of non-problem sports bettors (Hing, Russell, Li, et al., 2018), difficulties were encountered in 
recruiting a full sample of non-problem sports bettors who had gambled at least fortnightly in the preceding year (seven of the participants in the group did fit this criteria); accordingly, the frequency criterion for this group was relaxed to sports betting at-least-monthly in the past year. Other eligibility criteria were: agreeing to come to (anonymized location) campus for testing; agreeing to non-invasive sensors being placed on their skin; not taking certain medication/s that influence psychophysiological readings (e.g., for respiratory or gastrointestinal issues); and speaking English as their main language.

Sixty eligible participants attended our research laboratory; however, one participant was excluded from the statistical analyses, due to unsolvable eye-tracking calibration issues. Of the remaining 59 participants (47 males; age range $=19-65$ years, $M=39.70, S D=10.20)$, 12 were classified as non-problem gamblers, 10 as low-risk gamblers, 18 as moderate-risk gamblers, and 9 as problem gamblers based on the Problem Gambling Severity Index (PGSI; Ferris \& Wynne, 2001). Ten people who had not gambled on any gambling form in the past 12 months formed a non-gambler control group. Age $(p=.280)$, income $(p=.422)$, and level of education $(p=.297) \mathrm{did}$ not significantly differ between the groups. All participants had normal or corrected-to-normal vision, and no participants reported using nicotine, alcohol, prescription drugs that are known to affect the psychophysiological measures recorded, or illicit drugs in $12 \mathrm{hr}$ prior to testing.

\section{Materials}

Advertisement stimuli. Twelve different advertisements, which were recorded from actual television broadcasts, were presented to each participant (these advertisements aired on different television channels, during or around the broadcast of sporting events). Table 1 presents details on the six sports betting advertisements that are relevant to this study; the other six advertisements were for car companies and were not included in subsequent statistical analysis. The presentation of the advertisements was counterbalanced across participants in order to offset order effects (no significant effects of order were observed, $p=.874$ ). Attempts were made to keep the length of the advertisements uniform, but due to limited experimental control when using highly ecologically valid stimuli, this was not possible. Four of the gambling advertisements featured one type of $I O$, while the other two were general brand awareness (BA) advertisements that did not feature any specific IO. We attempted to find advertisements from one single gambling operator to control for differences between the advertisements (i.e., that were not related to inducement type), but were unable to do so: instead, all advertisements came from different gambling operators and preference/s of betting operators was controlled for in subsequent analyses.

Eye-tracking equipment. A Tobii X2-30 Compact Edition eye-tracker, using Tobii Studio 3.3.2 1150, Professional Edition software (Stockholm, Sweden) to present stimuli, was used. Data were recorded to an Acer laptop (Aspire V5431 Series, model MS2360, Jakarta, Indonesia). Participants were seated approximately $900 \mathrm{~mm}$ from the eye-tracker, and their binocular eye movements were captured (at a rate of $30 \mathrm{~Hz}$ ) during the viewing of each advertisement, in an unrestrained set up.

The data obtained from this device were quantified by two members of the research team, who watched the recorded eye-tracking videos, and coded the overall number of fixations on what they had previously agreed constituted responsible gambling information and IO information, in each gambling advertisement. Responsible gambling information was messages that promoted a safe gambling experience, and was designed to prevent and/or minimize harm from the advertised gambling product (e.g., "Is gambling a problem for you? Call Gambling Help on 1800858858 or visit 'gamblinghelponline.org.au"'). IO information included other text-based product offers (e.g., Hing, Sproston, et al., 2017). Interrater reliability was analyzed through intraclass correlation coefficients, based on a mean-rating $(k=2)$, absolute-agreement, and two-way mixed model. The $95 \%$ confidence intervals of intraclass correlation coefficient estimates for all IO and responsible gambling information fixation variables were greater than 0.98 , indicating excellent interrater reliability (Koo \& Li, 2016), and that the average fixation numbers of the values, coded by the two raters, was suitable for use in subsequent analyses.

\section{Measures}

The PGSI, of the Canadian Problem Gambling Index (Ferris \& Wynne, 2001), was used to assess participants' vulnerability toward experiencing gambling-related problems. Based on this questionnaire, participants were classified as follows: non-problem gamblers $=$ score of 0 ; low-risk gamblers $=$ score of 1 or 2 ; moderate-risk gamblers $=$ scores 3-7; and problem gamblers $=$ score $\geq 8$.

Before viewing the series of advertisements, participants also completed a battery of questionnaires. This included

Table 1. Details of each advertisement including the responsible gambling (RG) messages, and inducement offer (IO) information presented therein

\begin{tabular}{lcccc}
\hline Code & Length of advertisement & Length of RG information & Advertisement type (inducement) & Length of inducement offer \\
\hline A & 30 & 3.74 & IO (bonus bet) & 14.60 \\
B & 15 & 6.18 & OO (better odds) & 3.25 \\
C & 30 & 6.87 & IO (reduced risk) & 8.65 \\
D & 15 & 1.04 & IO (cash rebate) & 6.91 \\
E & 25 & 13.36 & BA (n/a) & - \\
F & 31 & 6.74 & BA (n/a) & - \\
\hline
\end{tabular}

Note. All times are displayed in seconds. BA: brand awareness. 
questions on: demographic variables, including age, gender, country of birth, highest level of education, personal annual pretax income, and native language; sports betting behaviors over the past 12 months (non-gamblers received a slightly shorter version of this questionnaire, since most of these questions were not applicable to them); preference of, and exposure to, different companies related to the advertisements; and recent medical and illicit/recreational drug use.

\section{Procedure}

All data were collected in an air-conditioned testing laboratory, with vents positioned, so that air was not blowing directly onto participants, to reduce the occurrence of eye blinks. Once the physiological recording equipment was fitted and calibrated, participants filled out the demographic and personality questionnaires. Following this, each participant watched a series of 12 short advertisements, while their physiological activity was recorded. A 2-min break flanked each of the 12 advertisements, which allowed time for participants to answer a subjective experience questionnaire for the preceding advertisement, and rest before presentation of the subsequent stimuli. During each 2-min interval, a countdown signaling the onset of the next advertisement appeared on the screen, so that participants were prepared to watch it, and would not be startled by unexpected stimuli.

\section{Statistical analyses}

To test the hypothesis that fewer fixations would be placed on responsible gambling information, compared to other, text-based wagering IO information, a repeated-measures analysis of variance (ANOVA) was conducted. Withinsubjects' independent variables were message type (two levels: wagering information and responsible gambling information) and advertisement (four levels: Advertisement $A$, Advertisement $B$, Advertisement $C$, and Advertisement $D$ ). The between-subjects' independent variable was $P G S I$ group (five levels: non-gambler, non-problem gambler, low-risk gambler, moderate-risk gambler, and problem gambler). The dependent variable was the weighted number of fixations, which was calculated as the proportion of the amount of time that the relevant information was available for viewing to the total length of time the advertisement was shown on screen. The former was calculated by taking the average of the times recorded by two members of the research team [the interrater reliability was, again, analyzed through intraclass correlation coefficients, based on a mean rating $(k=2)$, absolute-agreement, and two-way mixed model, and returned a 95\% confidence interval result of greater than .99; Koo \& Li, 2016]. A follow-up repeatedmeasures ANOVA was also conducted to directly compare whether the number of fixations on each advertisement differed between gambler (non-problem gambler, low-risk gambler, moderate-risk gambler, and problem gambler groups, combined) and non-gambler groups, as a function of message type and advertisement type, as described above.

To further investigate how much responsible gambling messages were looked at within each of the advertisements, a separate repeated-measures ANOVA was conducted, with the addition of two other, general BA advertisements. For this analysis, advertisement type served as the withinsubjects independent variable (with six levels; see Table 1), PGSI group as a between-subjects independent variable (with four levels: non-problem gambler, low-risk gambler, moderate-risk gambler, and problem gambler groups), and the weighted number of fixations as the dependent variable.

\section{Ethics}

This project was approved by the CQUniversity Australia Human Research Ethics Committee (Project approval no.: H16/09-256). All participants were fully informed of the study protocol, advised that they were free to withdraw from the study at any time, and provided their consent to participate before testing commenced.

\section{RESULTS}

Analysis of the structural features of the responsible gambling information showed that messages were generally presented at the bottom of the screen in small, white/light gray font, which remained static after its initial presentation on-screen. They were also presented without any stimulusspecific auditory information (i.e., the only attendant auditory stimuli were related to the broader advertisement and not the content of these messages). The amount of time these messages was presented varied (see Table 1), as did the times these messages were first presented within the advertisement (with some presented from the beginning, whereas others started later). All messages, with the exception of the one in Advertisement A, were presented in a naturalistic manner (e.g., on top of a background scene), rather than on a block-color background, minimizing the contrast between the message and the rest of the content on-screen.

With regard to the first hypothesis, a significant main effect of message type was found, $F(1,54)=71.45$, $p<.001, \eta^{2}=0.57$, with participants placing a greater number of fixations on the $I O$ information $(M=1.68$; $S E=0.12)$ compared to the responsible gambling information $(M=0.46 ; S E=0.10)$. A significant Message type $\times$ Advertisement type interaction was also found, $F(3,162)=$ $8.86, p<.001, \eta^{2}=0.14$, indicating that the number of fixations on the responsible gambling information did not uniformly reflect (inversely or otherwise) the number of fixations on the inducement information, and that the wider context of the advertisement influenced fixations. The Message type $\times$ Advertisement type $\times$ PGSI group interaction was not significant $(p=.205)$.

The main effect of PGSI group was not significant $(p=.234)$, nor was the Message type $\times$ PGSI group interaction $(p=.272)$, when all groups were compared in the analysis; however, follow-up analysis revealed preliminary evidence for a Message type $\times$ PGSI group interaction, with gambling participants more likely to look more at inducement information, whereas the non-gamblers were more likely to look at responsible gambling messages $(p=.056)$. The average proportion of fixations placed on responsible gambling messages (as a function of the total number of fixations on text-based information across all 
advertisements) was $14.76 \%$ across all gambling groups, compared to $29.4 \%$ for the non-gambling group. There was also some evidence for the relationship between message type and advertisement type to differ according to PGSI group (i.e., comparing gambling and non-gambling participants; $p=.067$ ), but the Advertisement type $\times$ PGSI group interaction effect was not significant ( $p=.431$; see Figure 1).

The results relating to the third exploratory analysis revealed a significant main effect of advertisement type, $F(5,270)=13.74, p<.001, \eta^{2}=0.20$. Pairwise comparisons, with Bonferroni corrections, revealed that the number of fixations on Advertisement $A$ was significantly greater than all other advertisement types, and that the number of fixations on Advertisement $B$ was significantly less than all other advertisement types $(p<.05)$. A significant interaction between advertisement type and PGSI group was also found, $F(15,225)=2.27, p=.006, \eta^{2}=0.13$, although the main effect of PGSI group was not statistically significant $(p=.134$; see Figure 2).

\section{DISCUSSION}

This is the first study to examine how much responsible gambling messages, presented in televised sports betting advertisements, are looked at by community gamblers, using eye-tracking technology. As hypothesized, gamblers were more likely to place a greater number of weighted fixations on inducement information, compared to responsible gambling messages; more specifically, they placed less than $15 \%$ of the

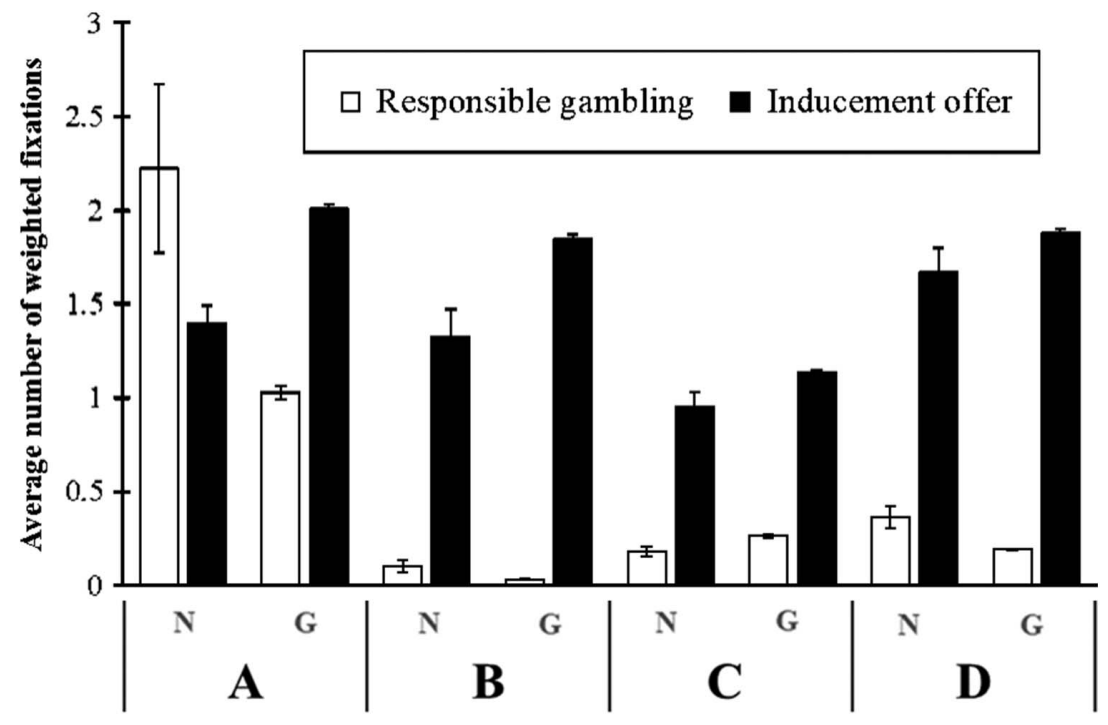

Figure 1. The weighted number of fixations on inducement offer and responsible gambling messages for each advertisement containing the former, according to risk of gambling problems (where N: non-gambler; G: non-problem gambler, low-risk gambler, moderate-risk gambler, and problem gambler groups, combined). Error bars represent $\pm 1 S E$

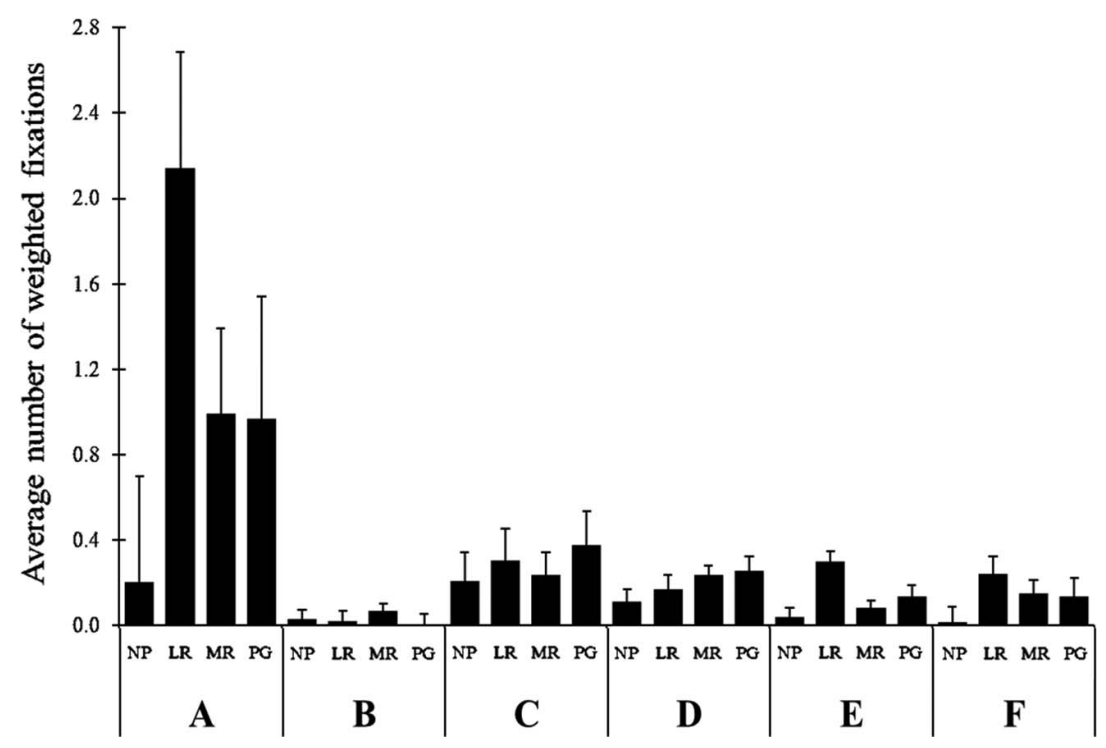

Figure 2. The weighted number of fixations on responsible gambling messages for each advertisement, according to risk of gambling problems (where NP: non-problem gambler; LR: low-risk gambler; MR: moderate-risk gambler; PG: problem gambler).

Error bars represent $\pm 1 S E$ 
total number of fixations on, or near, the latter, across all advertisements viewed. This finding supports the contention that this type of responsible gambling initiative is highly ineffective (Lamont, Hing, \& Vitartas, 2016; Sproston et al., 2015). Although the number of fixations placed on responsible gambling versus IO information did not differ between at-risk gambling groups, preliminary findings suggest that, particularly when presented in certain formats, non-gamblers are actually more likely to look at the former message type. This finding is consistent with previous research that shows wagering advertisements have limited appeal for those not already involved in sports betting activity (Binde, 2009; Hing, Cherney, et al., 2014).

The results also showed that the number of fixations on responsible gambling messages does not appear to reflect the total length of the advertisement, nor the length of the IO (if applicable; see Table 1). The greater number of fixations placed on the responsible gambling information in Advertisement A, compared to all other advertisements, is likely to reflect the more conspicuous physical characteristics of this advertisement; specifically, the presentation of this message on a solid/block-color background, as opposed to a naturalistic setting. Further research is needed to verify this, as well as to investigate the reason/s why Advertisement $B$ was looked at so little in comparison to the other advertisements, and why the different number of fixations placed on the advertisements varied according to risk of gambling problems. It is possible that the between-group differences may reflect the wider context (e.g., the appeal of different IOs presented and motivations to gamble) and other characteristics of the advertisements' content (e.g., LopezGonzalez, Estévez, \& Griffiths, 2017a; Lopez-Gonzalez, Guerrero-Solé, Estévez, \& Griffiths, 2017; Lopez-Gonzalez, Guerrero-Solé, \& Griffiths, 2017). It is also possible that they merely reflect random noise in the data, since all of these messages were looked at so little; however, future research should seek to verify if this is the case, or if these differences reflect meaningful, but subtle, variations in these messages.

Closer inspection of the characteristics of the responsible gambling messages across all advertisements revealed several similarities, including that they were presented in very small, static, and feint font, especially in comparison to the dynamic, colorful, and often humorous and/or highdrama betting-related content. As mentioned above, in all cases except one (Advertisement $A$ ), the messages were presented on a naturalistic background, with limited contrast between the message and the scene, meaning that they did not stand out to their maximum potential. The advertisement that garnered the greatest number of fixations was the one with a contrasting background, highlighting the benefit of including messages that are more visible. Responsible gambling messages were also presented without attendant auditory stimuli to draw attention to them, in comparison to the upbeat and exciting soundtrack of the rest of the advertisement, which focused on the $I O$ and $B A$ information.

While this study provides valuable information on the possible impact responsible gambling messages have on viewers' attention, several caveats need to be mentioned. First, the study was conducted in a laboratory environment using recorded advertisements, with which participants may be quite familiar. Although the preference of betting operators was controlled for in this study, the number of times the advertisement was seen before was not. Future research should ideally present a greater range of advertisements to participants, and assess the impact familiarity has on results. Moreover, this study did not explicitly ask participants, if they could actually recall the content of the messages viewed. It is possible that viewers did actually read the messages, but because they are so well-versed in such, did not bother to spend more time looking at them. Based on previous research (Hing, 2003; Monaghan, 2004; Monaghan \& Blaszczynski, 2007; Steenbergh et al., 2004; Williams \& Connolly, 2006), this is unlikely to be the case, but future research on this topic should control for this more carefully. Finally, the study is based on a quasi-experimental cross-sectional design, and did not link viewing of advertisements, or the associated viewing of responsible gambling messages to actual behavior.

Future research could also focus on experimentally manipulating the physical characteristics of responsible gambling information (e.g., the size, duration, placement of text, etc.) and examining the effects on attention. It could also investigate exactly what aspect/s of the messages are being focused on (e.g., "Gamble Responsibly" messages, helpline information, etc.). Such information has the potential to be applied to the development of safer advertising materials that reduce the risk of vulnerable individuals, while also allowing betting agencies to use advertising material to support their business. Strategies to increase the impact of these messages might include having a person presenting the reminder to gamble responsibly (Hing, Vitartas, \& Lamont, 2017), or otherwise encourage positive play (Wood \& Griffiths, 2015), and referring to the actual risks and/or chances of winning (Gordon, Gurrieri, \& Chapman, 2015). Other options may be to: include a non-static display, as these have been shown to be recalled more effectively than static messages, both immediately after presentation, and at 2 weeks after viewing (Monaghan \& Blaszczynski, 2010), to display messages in isolation, so that they do not compete with other content within the advertisement, and/or to display these on blockcolor background. It would also be useful to investigate the relationship between self-reported attitudes toward responsible gambling, these messages, and the amount of attention paid to these, so that more-targeted approaches to achieving safe gambling can be developed.

This study offers an interesting and novel approach to answer the question of the extent to which responsible gambling messages in sports betting advertisements are being looked at by viewers. The results suggest that, in their most common format, they are doing little to garner the attention of those at risk of gambling harm, or those who do not experience problems as a result of their gambling, particularly when the focus of these advertisements is on the wagering opportunities being presented. It is likely that the characteristics of these messages, such as their placement on the screen, their size, feint font, and lack of attendant auditory stimuli, are among some of the reasons for the glaring lack of fixations placed on them. The information provided in this study, in conjunction with further research, may offer some useful strategies in countering any negative effects of exposure to wagering advertising in the sports betting domain. 
Funding sources: This study was funded by the Victorian Responsible Gambling Foundation. The project was entitled "Effect of Wagering Marketing on Vulnerable Adults."

Authors' contribution: All the authors designed the study and conducted data collection. NH led the overall project. LL led this stage of the overall project and conducted the data analysis. All the authors were involved in the drafting of the manuscript, read, and commented on the manuscript and approved it for submission.

Conflict of interest: LL has received research funding from the Victorian Responsible Gambling Foundation, CQUniversity Australia, and Aristocrat Pty Ltd., through an industry-funded Australian Post-Graduate Award. She declares that he has no conflict of interest in relation to this manuscript.

EL has received research grants from the Victorian Responsible Gambling Foundation and Gambling Research Australia. He declares that he has no conflict of interest in relation to this manuscript.

AMR has received research funding from the Victorian Responsible Gambling Foundation, Queensland Justice and Attorney-General, Gambling Research Australia, National Association for Gambling Studies, Australian Communications and Media Authority, and the Alberta Gambling Research Institute. He has received industry funding for an evaluation of problem gambling among casino employees from Echo/Star Entertainment Group. He is also affiliated to the University of Sydney. He declares that he has no conflict of interest in relation to this manuscript.

NG has received research funding from the Victorian Responsible Gambling Foundation and Australia's National Research Organisation for Women's Safety. She declares that he has no conflict of interest in relation to this manuscript.

HT declares that he has no conflict of interest in relation to this manuscript.

NH has received research funds from the Victorian Responsible Gambling Foundation, Gambling Research Australia, Australian Department of Social Services, Alberta Gambling Research Institute, the Australian Gambling Research Centre, the Queensland, New South Wales, Victorian and South Australian Governments, the Australian Research Council, Australia's National Research Organisation for Women's Safety, and the First Nations Foundation. She has also received consultancy funds from Echo Entertainment and Sportsbet, and an honorarium from Singapore Pools for membership of its International Advisory Committee. She declares that he has no conflict of interest in relation to this manuscript.

\section{REFERENCES}

Australian Association of National Advertisers. (2018). Wagering advertising code. Retrieved from http://aana.com.au/content/ uploads/2018/05/180315-Wagering-Advertising-Code-PracticeNote.pdf
Australian Communications and Media Authority. (2018). New gambling advertising rules during live sports. Retrieved from https://www.acma.gov.au/Industry/Broadcast/Television/ Advertising/new-gambling-advertising-rules-during-live-sports

Australian Government Department of Communications and the Arts. (2017). Gambling advertising: Broadcasting and content reform. Retrieved from https://www.communications. gov.au/sites/g/files/net301/f/factsheet_gambling_advertising. pdf

Bailey, B. P., Konstan, J. A., \& Carlis, J. V. (2001). The effects of interruptions on task performance, annoyance, and anxiety in the user interface. Interact, 1, 593-601.

Bartram, L. (2001). Enhancing information visualization with motion (Unpublished doctoral dissertation). Simon Fraser University, Burnaby, Canada.

Binde, P. (2009). Exploring the impact of gambling advertising: An interview study of problem gamblers. International Journal of Mental Health and Addiction, 7(4), 541-554. doi:10.1007/ s11469-008-9186-9

Binde, P. (2014). Gambling advertising: A critical research review. London, UK: Responsible Gambling Trust.

Browne, M., Hing, N., Russell, A. M. T., Thomas, A., \& Jenkinson, R. (2019). The impact of exposure to wagering advertisements and inducements on intended and actual betting expenditure: An ecological momentary assessment study. Journal of Behavioral Addictions, 8(1), 146-156. doi:10.1556/ 2006.8.2019.10

Campbell, C. S., \& Smith, G. J. (2003). Gambling in Canada: From vice to disease to responsibility: A negotiated history. Canadian Bulletin of Medical History, 20(1), 121-149. doi:10.3138/cbmh.20.1.121

Clark, E., \& Brock, T. (1994). Warning label location, advertising, and cognitive responding. In E. Clark, T. Brock, \& D. Stewart (Eds.), Attention, attitude, and affect in responding to advertising (pp. 287-299). Hillsdale, NJ: Lawrence Erlbaum Associates.

Cuesta-Cambra, U., Manas-Viniegra, L., Nino-Gonzalez, J. I., \& Martinez-Martinez, L. (2019). Cognitive processing of advertising self-regulation of online gambling in university students. Revista Mediterránea de Comunicación, 10(2), 1-16. doi:10.14198/MEDCOM2019.10.2.4

Delfabbro, P. H. (2008). Australasian gambling review (3rd ed.). Adelaide, Australia: Independent Gambling Authority.

Delfabbro, P. H. (2012). Australasian gambling review (5th ed.). Adelaide, Australia: Independent Gambling Authority.

Derevensky, J., Sklar, A., Gupta, R., \& Messerlian, C. (2010). An empirical study examining the impact of gambling advertisements on adolescent gambling attitudes and behaviours. International Journal of Mental Health and Addiction, 8(1), 21-34. doi:10.1007/s11469-009-9211-7

Federal Register of Legislation. (1992). Broadcasting Services Act 1992 (Cth). Retrieved from https://www.legislation.gov.au/ Details/C2018C00375

Ferris, J., \& Wynne, H. (2001). The Canadian Problem Gambling Index. Ottawa, ON: Canadian Centre on Substance Abuse.

Focal Research. (2004). NS VL responsible gaming features evaluation: Final report. Nova Scotia, Canada: Focal Research Consultants, Ltd.

Gainsbury, S., Russell, A., Hing, N., Wood, R., Lubman, D., \& Blaszczynski, A. (2013). How the Internet is changing gambling: Findings from an Australian prevalence survey. 
Journal of Gambling Studies, 31(1), 1-15. doi:10.1007/ s10899-013-9404-7

Gordon, R., Gurrieri, L., \& Chapman, M. (2015). Broadening an understanding of problem gambling: The lifestyle consumption community of sports betting. Journal of Business Research, 68(10), 2164-2172. doi:10.1016/j.jbusres.2015.03.016

Hancock, L., Schellinck, T., \& Schrans, T. (2008). Gambling and corporate social responsibility (CSR): Re-defining industry and state roles on duty of care, host responsibility and risk management. Policy and Society, 27(1), 55-68. doi:10.1016/j. polsoc.2008.07.005

Hancock, L., \& Smith, G. (2017). Critiquing the Reno model I-IV international influence on regulators and governments (2004-2015) - The distorted reality of "responsible gambling." International Journal of Mental Health and Addiction, 15(6), 1151-1176. doi:10.1007/s11469-017-9746-y

Hing, N. (2003). An assessment of member awareness, perceived adequacy and perceived effectiveness of responsible gambling strategies in Sydney clubs. Lismore, Australia: Centre for Gambling Education and Research.

Hing, N., Cherney, L., Blaszczynski, A., Gainsbury, S., \& Lubman, D. (2014). Do advertising and promotions for online gambling increase gambling consumption? An exploratory study. International Gambling Studies, 14(3), 394-409. doi:10.1080/14459795.2014.903989

Hing, N., Lamont, M., Vitartas, P., \& Fink, E. (2015a). How sports bettors respond to sports-embedded gambling promotions: Implications for compulsive consumption. Journal of Business Research, 68(10), 2057-2066. doi:10.1016/j.jbusres. 2015.03.003

Hing, N., Lamont, M., Vitartas, P., \& Fink, E. (2015b). Sports-embedded gambling promotions: A study of exposure, sports betting intention and problem gambling amongst adults. International Journal of Mental Health and Addiction, 13(1), 115-135. doi:10.1007/s11469-014-9519-9

Hing, N., Russell, A. M. T., \& Hronis, A. (2018). A definition and set of principles for responsible consumption of gambling. International Gambling Studies, 18, 359-382. doi:10.1080/ 14459795.2017.1390591

Hing, N., Russell, A. M. T., Li, E., \& Vitartas, P. (2018). Does the uptake of wagering inducements predict impulse betting on sport? Journal of Behavioral Addictions, 7(1), 146-157. doi:10.1556/2006.7.2018.17

Hing, N., Russell, A. M. T., Thomas, A., \& Jenkinson, R. (2019). Wagering advertisements and inducements: Exposure and perceived influence on betting behavior. Journal of Gambling Studies, 35, 793-811. doi:10.1007/s10899-018-09823-y

Hing, N., Russell, A. M. T., Vitartas, P., \& Lamont, M. (2016). Demographic, behavioural and normative risk factors for gambling problems amongst sports bettors. Journal of Gambling Studies, 32(2), 625-641. doi:10.1007/s10899-0159571-9

Hing, N., Sproston, K., Brook, K., \& Brading, R. (2017). The structural features of sports and race betting inducements: Issues for harm minimisation and consumer protection. Journal of Gambling Studies, 33(2), 685-704. doi:10.1007/s10899016-9642-6

Hing, N., Vitartas, P., \& Lamont, M. (2017). Understanding persuasive attributes of sports betting advertisements: A conjoint analysis of selected elements. Journal of Behavioral Addictions, 6(4), 658-668. doi:10.1556/2006.6.2017.062
Hing, N., Vitartas, P., Lamont, M., \& Fink, E. (2014). Adolescent exposure to gambling promotions during televised sport: An exploratory study of links with gambling intentions. International Gambling Studies, 14(3), 374-393. doi:10.1080/1445 9795.2014.902489

Humphreys, B. R., \& Perez, L. (2012). Who bets on sports? Characteristics of sports bettors and the consequences of expanding sports betting opportunities. Estudios de Economía Aplicada, 30, 579-597.

Jenkinson, R., de Lacy-Vawdon, C., \& Carroll, M. (2018). Weighing up the odds: Young men, sports and betting. Melbourne, Australia: Victorian Responsible Gambling Foundation.

Johansson, A., Grant, J. E., Kim, S. W., Odlaug, B. L., \& Götestam, K. G. (2009). Risk factors for problematic gambling: A critical literature review. Journal of Gambling Studies, 25(1), 67-92. doi:10.1007/s10899-008-9088-6

Johnston, W., \& Dark, V. (1986). Selective attention. Annual Review of Psychology, 37(1), 43-75. doi:10.1146/annurev. ps.37.020186.000355

Kim, H. S., Wohl, M. J. A., Stewart, M. J., Sztainert, T., \& Gainsbury, S. M. (2014). Limit your time, gamble responsibly: Setting a time limit (via pop-up message) on an electronic gaming machine reduces time on device. International Gambling Studies, 14(2), 266-278. doi:10.1080/144597 95.2014.910244

Koo, T. K., \& Li, M. Y. (2016). A guideline of selecting and reporting intraclass correlation coefficients for reliability research. Journal of Chiropractic Medicine, 15(2), 155-163. doi:10.1016/j.jcm.2016.02.012

Lamont, M., Hing, N., \& Vitartas, P. (2016). Affective responses to gambling promotions during televised sport: A qualitative analysis. Sport Management Review, 19(3), 319-331. doi:10.1016/j.smr.2015.06.002

Livingstone, C., \& Woolley, R. (2007). Risky business: A few provocations on the regulation of electronic gaming machines. International Gambling Studies, 7(3), 361-376. doi:10.1080/ 14459790701601810

Lopez-Gonzalez, H., Estévez, A., \& Griffiths, M. D. (2017a). Controlling the illusion of control: A grounded theory of sports betting advertising in the UK. International Gambling Studies, 18(1), 39-55. doi:10.1080/14459795.2017.1377747

Lopez-Gonzalez, H., Estévez, A., \& Griffiths, M. D. (2017b). Marketing and advertising online sports betting: A problem gambling perspective. Journal of Sport and Social Issues, 41(3), 256-272. doi:10.1177/0193723517705545

Lopez-Gonzalez, H., Guerrero-Solé, F., Estévez, A., \& Griffiths, M. (2017). Betting is loving and bettors are predators: A conceptual metaphor approach to online sports betting advertising. Journal of Gambling Studies, 34(3), 709-726. doi:10.1007/s10899-017-9727-x

Lopez-Gonzalez, H., Guerrero-Solé, F., \& Griffiths, M. D. (2017). A content analysis of how 'normal' sports betting behaviour is represented in gambling advertising. Addiction Research and Theory, 26(3), 238-247. doi:10.1080/16066359.2017. 1353082

Monaghan, S. (2004). Recall of legislated electronic gaming machine signs and irrational cognitions and beliefs regarding gambling (Unpublished honours dissertation). University of Sydney, Sydney, Australia.

Monaghan, S., \& Blaszczynski, A. (2007). Recall of electronic gaming machine signs: A static versus a dynamic mode of 
presentation. Journal of Gambling Issues, 20(20), 253-268. doi:10.4309/jgi.2007.20.8

Monaghan, S., \& Blaszczynski, A. (2010). Impact of mode of display and message content of responsible gambling signs for electronic gaming machines on regular gamblers. Journal of Gambling Studies, 26, 67-88. doi:10.1007/s10899-009-9150-Z

Monaghan, S., Derevensky, J., \& Sklar, A. (2008). Impact of gambling advertisements and marketing on children and adolescents: Policy recommendations to minimise harm. Journal of Gambling Issues, 22(22), 252-272. doi:10.4309/jgi.2008.22.7

Parke, A., Harris, A., Parke, J., Rigbye, J., \& Blaszczynski, A. (2014). Facilitating awareness and informed choice in gambling. The Journal of Gambling Business and Economics, 8(3), 6-20. doi:10.5750/jgbe.v8i3.971

Productivity Commission. (2010). Gambling inquiry report. Canberra, Australia: Commonwealth of Australia.

Rayner, K., Rotello, C. M., Stewart, A. J., Keir, J., \& Duffy, S. A. (2001). Integrating text and pictorial information: Eye movements when looking at print advertisements. Journal of Experimental Psychology: Applied, 7, 219-26. doi:10.1037/1076-898x.7.3.219

Reith, G. (2007). Gambling and the contradictions of consumption: A genealogy of the "pathological" subject. American Behavioral Scientist, 51(1), 33-55. doi:10.1177/0002764207304856

Reith, G. (2008). Reflections on responsibility. Journal of Gambling Issues, 22(22), 149-155. doi:10.4309/jgi.2008.22.12

Russell, A. M. T., Hing, N., Browne, M., \& Rawat, V. (2018). Are direct messages (texts and emails) from wagering operators associated with betting intention and behaviour? An ecological momentary assessment study. Journal of Behavioral Addictions, 7(4), 1079-1090. doi:10.1556/2006.7.2018.99

Schüll, N. D. (2012). Addiction by design: Machine gambling in Las Vegas. Princeton, NJ: Princeton University Press.

Sproston, K., Hanley, C., Brook, K., Hing, N., \& Gainsbury, S. (2015). Marketing of sports betting and racing. Melbourne, Australia: Gambling Research Australia.
Steenbergh, T. A., Whelan, J. P., Meyers, A. W., May, R. K., \& Floyd, K. (2004). Impact of warning and brief intervention messages on knowledge of gambling risk, irrational beliefs and behaviour. International Gambling Studies, 4(1), 3-16. doi:10.1080/1445979042000224377

Stewart, M. J., \& Wohl, M. J. A. (2012). Pop-up messages, dissociation, and craving: How monetary limit reminders facilitate adherence in a session of slot machine gambling. Psychology of Addictive Behaviours, 27(1), 268-273. doi:10.1037/a0029882

Thomas, S. L., Lewis, S., McLeod, C., \& Haycock, J. (2012). 'They are working every angle.' A qualitative study of Australian adults' attitudes towards, and interactions with, gambling industry marketing strategies. International Gambling Studies, 12(1), 111-127. doi:10.1080/14459795. 2011.639381

Williams, R. J., \& Connolly, D. (2006). Does learning about the mathematics of gambling change gambling behavior? Psychology of Addictive Behaviors, 20(1), 62-68. doi:10.1037/0893164X.20.1.62

Williams, R. J., Volberg, R. A., \& Stevens, R. M. G. (2012). The population prevalence of problem gambling: Methodological influences, standardized rates, jurisdictional differences, and worldwide trends. Guelph, Canada: Ontario Problem Gambling Research Centre and the Ontario Ministry of Health and Long Term Care.

Williams, R. J., West, B. L., \& Simpson, R. I. (2012). Prevention of problem gambling: A comprehensive review of the evidence, and identified best practices. Guelph, Canada: Ontario Problem Gambling Research Centre and the Ontario Ministry of Health and Long Term Care.

Wood, R. T. A., \& Griffiths, M. D. (2015). Understanding positive play: An exploration of playing experiences and responsible gambling practices. Journal of Gambling Studies, 31(4), 17151734. doi:10.1007/s10899-014-9489-7 